\title{
Coordinately express hemicellulolytic enzymes in Kluyveromyces marxianus to improve the saccharification and ethanol production from corncobs
}

\author{
Qing Lan ${ }^{1,2}$, Yitong Duan ${ }^{1,2}$, Pingping Wu ${ }^{1,2}$, Xueyin $\mathrm{Li}^{1,2}$, Yao Yu ${ }^{1,2}$, Bo Shi ${ }^{4}$, Jungang Zhou ${ }^{1,2^{*}}$ (D) and Hong $\mathrm{Lu}^{1,2,3^{*}}$
}

\begin{abstract}
Background: Hemicellulose acts as one factor contributing to the recalcitrance of lignocellulose that prevents cellulases to degrade the cellulose efficiently even in low quantities. Supplement of hemicellulases can enhance the performance of commercial cellulases in the enzymatic hydrolyses of lignocellulose. Kluyveromyce marxianus is an attractive yeast for cellulosic ethanol fermentation, as well as a promising host for heterologous protein production, since it has remarkable thermotolerance, high growth rate, and broad substrate spectrum etc. In this study, we attempted to coordinately express multiple hemicellulases in K. marxianus through a 2A-mediated ribosome skipping to self-cleave polyproteins, and investigated their capabilities for saccharification and ethanol production from corncobs.
\end{abstract}

Results: Two polycistronic genes IMPX and IMPaX were constructed to test the self-cleavage of P2A sequence from the Foot-and-Mouth Disease virus (FMDV) in K. marxianus. The IMPX gene consisted of a $\beta$-mannanase gene M330 (without the stop codon), a P2A sequence and a $\beta$-xylanase gene Xyn-CDBFV in turn. In the IMPaX gene, there was an additional a-factor signal sequence in frame with the $\mathrm{N}$-terminus of $X y n-C D B F V$. The extracellular $\beta$-mannanase activities of the IMPX and IMPaX strains were 21.34 and $15.50 \mathrm{U} / \mathrm{mL}$, respectively, but the extracellular $\beta$-xylanase activity of IMPaX strain was much higher than that of the IMPX strain, which was 136.17 and $42.07 \mathrm{U} / \mathrm{mL}$, respectively. Subsequently, two recombinant strains, the IXPaR and IMPaXPaR, were constructed to coordinately and secretorily express two xylantic enzymes, Xyn-CDBFV and $\beta$-D-xylosidase RuXyn1, or three hemicellulolytic enzymes including M330, Xyn-CDBFV and RuXyn1. In fed-batch fermentation, extracellular activities of $\beta$-xylanase and $\beta$-xylosidase in the IXPaR strain were 1664.2 and $0.90 \mathrm{U} / \mathrm{mL}$. Similarly, the IMPaXPaR strain secreted the three enzymes, $\beta$-mannanase, $\beta$-xylanase, and $\beta$-xylosidase, with the activities of $159.8,2210.5$, and $1.25 \mathrm{U} / \mathrm{mL}$, respectively. Hemicellulolases of both strains enhanced the yields of glucose and xylose from diluted acid pretreated (DAP) corncobs when acted synergistically with commercial cellulases. In hybrid saccharification and fermentation (HSF) of DAP corncobs, hemicellulases of the IMPaXPaR strain increased the ethanol yield by $8.7 \%$ at $144 \mathrm{~h}$ compared with the control. However, both ethanol and xylose yields were increased by 12.7 and 18.2\%, respectively, at $120 \mathrm{~h}$ in HSF of aqueous ammonia pretreated (AAP) corncobs with this strain. Our results indicated that coordinate expression of hemicellulolytic enzymes in $K$. marxianus promoted the saccharification and ethanol production from corncobs.

\footnotetext{
*Correspondence: zhoujg@fudan.edu.cn; honglv@fudan.edu.cn

${ }^{1}$ State Key Laboratory of Genetic Engineering, School of Life Sciences,

Fudan University, 2005 Songhu Road, Shanghai 200438, People's Republic

of China

Full list of author information is available at the end of the article
}

(c) The Author(s) 2021. Open Access This article is licensed under a Creative Commons Attribution 4.0 International License, which permits use, sharing, adaptation, distribution and reproduction in any medium or format, as long as you give appropriate credit to the original author(s) and the source, provide a link to the Creative Commons licence, and indicate if changes were made. The images or other third party material in this article are included in the article's Creative Commons licence, unless indicated otherwise in a credit line to the material. If material is not included in the article's Creative Commons licence and your intended use is not permitted by statutory regulation or exceeds the permitted use, you will need to obtain permission directly from the copyright holder. To view a copy of this licence, visit http://creativecommons.org/licenses/by/4.0/. The Creative Commons Public Domain Dedication waiver (http://creativeco mmons.org/publicdomain/zero/1.0/) applies to the data made available in this article, unless otherwise stated in a credit line to the data. 
Conclusions: The FMDV P2A sequence showed high efficiency in self-cleavage of polyproteins in K. marxianus and could be used for secretory expression of multiple enzymes in the presence of their signal sequences. The IMPaXPaR strain coexpressed three hemicellulolytic enzymes improved the saccharification and ethanol production from corncobs, and could be used as a promising strain for ethanol production from lignocelluloses.

Keywords: Kluyveromyces marxianus, Hemicellulases, Ribosomes skipping, Enzymatic hydrolysis, Ethanol

\section{Background}

Lignocellulose is the most abundant renewable resource on earth, which is recalcitrance and compact biomass that composes of directly interlinked cellulose, hemicelluloses and lignin. Utilization of lignocellulosic biomass is a feasible solution to avoid excessive reliance on fossil fuels, and alleviates global warming and environmental pollution events [1]. Unlike first-generation biofuels used edible feedstocks, cellulosic ethanol is the second-generation biofuel manufactured from non-edible carbohydrates of plant cell walls [2]. This progress is expected to avert the competition for food and energy demand concurrent with the growth of the world population that has exerted great stress on current agriculture, and provided more environmental benefits as it was carbon-neutral avoiding an increase of greenhouse gases in the atmosphere $[3,4]$. Generally, bioethanol is used alone, or mixed in varying amounts with gasoline, and is a more uniform and cleaner source of fuel than the other two biofuels, biodiesel and biogas, that are samely made from living matter. However, both biodiesel and biogas suffer uncertain combustion standardizations because their cetane numbers or gelatinization temperatures highly depend on the source of lipid or the methane content that varies with the substrate composition and digestion method [5]. Bioethanol production is basically composed of four phases that include pretreatment, hydrolysis, fermentation and dehydration. Hydrolysis (saccharification) of pretreated lignocelluloses is a critical prerequisite for ethanolic fermentation by microbes, but usually, it can be concurrently integrated with fermentation, known as simultaneous saccharification and fermentation (SSF), when using enzymes for the hydrolysis [6].

To depolymerize lignocelluloses into fermentable sugars, at least three types of cellulases, such as $\beta$-1,4-endoglucanase, exocellobiohydrolase, and $\beta-1,4$ glucosidase, and a remarkable diversity of hemicellulases including $\beta-1,4$-xylanase, $\beta-1,4$-xylosidase, $\beta$-1,4-mannanase, $\alpha$-arabinosidases, esterases, etc., are required to act synergistically. But the less catalytic efficiency and high cost of enzymes made the cellulose hydrolysis become the major bottleneck for bringing down the production cost of biofuel from lignocelluloses $[7,8]$. A consolidated bioprocessing (CBP) strategy that integrated enzyme production, saccharification, and fermentation in one step is well accepted as an attractive approach to reduce the cost of biofuel production [9]. Despite the conventional yeasts and bacteria for separated hydrolysis and fermentation (SHF) and SSF processes are well established, the use of ideal CBP is still on the way. Recently, a hybrid saccharification and fermentation (HSF), also called hybrid hydrolysis and fermentation (HHF), is set out by hydrolyzing pretreated lignocelluloses with cellulases before a CBP or SSF process $[10,11]$.

CBP microbes for cellulosic ethanol were genetically modified from either natural cellulolytic bacteria (Cellulolytic thermophiles, Thermoanaerobacterium saccharolyticum, Caldicellulosiruptor bescii, etc.) and filamentous fungi (Trichoderma reesei, Aspergillus niger, Fusarium oxysporum, and Penicillium oxalicum etc.), or ethanologenic microorganisms including Saccharomyces cerevisiae, Kluyveromyces marxianus, Zygosaccharomyces bailii and Zymomonas mobilis, that have combined the cellulase production, enzymatic hydrolysis, and microbial fermentation into a single operation [12]. But the low ethanol tolerance is an actual inferiority for cellulolytic microbes, since distillation of ethanol is an energy-intensive process and it consumes more of heat to separate ethanol from a lower concentration fermentation [12, 13]. Co-fermentation of pentoses, xylose and arabinose, is a reasonable way to raise the bioethanol concentration from lignocellulosic biomass and reduce the cost of cellulosic ethanol at the same time [14]. As the most utilized yeast for ethanol fermentation, S. cerevisiae is unable to assimilate xylose and other C5 sugars, which impedes the efficient ethanol conversion from lignocellulose even it has high ethanol productivity and tolerance [15]. $K$. marxianus is regarded as another attractive yeast for ethanolic fermentation due to its abilities of fastest growth, remarkable thermotolerance, and broad substrate spectrum including glucose, mannose, galactose, lactose, cellobiose, the pentose sugars xylose and arabinose that are virtually presented in all enzymatic hydrolysates of pretreated lignocelluloses [16-18]. Factually, either in SSF or HSF, high-temperature fermentation can significantly elevate the efficiency of lignocellulose hydrolysis, decrease the risk of contamination, and curtail the ethanol production phase [6]. 
To be ethanologenic CBP strains, enzymes responsible for cellulose hydrolysis are required to simultaneously express in one host, while the genetic basis of $K$. marxianus is less well understood [19]. A synthetic biology technique termed "Promoter-based Gene Assembly and Simultaneous Overexpression (PGASO)" was developed to integrate gene cassettes into the $K$. marxianus KY3 genome in a single step, with each gene expression regulated by an individual promoter along with a terminator [20]. In K. marxianus, however, the frequency of double homologous recombination is very low, even flanked with long homologous fragments [21]. On the contrary, it has a high activity of non-homologous end-joining (NHEJ) that can efficiently integrate non-homologous DNA fragments into chromosomes via fusing two DNA strands together in the absence of specific sequences [22, 23]. This feature is disadvantageous to integrate expression cassettes into the specific target loci. Herein, we incorporated a different way for co-expression of multiple hemicellulases in one replicative plasmid using a P2A self-processing peptide from foot-and-mouth disease virus (FMDV) in $K$. marxianus. P2A sequences are relatively short oligopeptides located between the P1 and P2 proteins in some picornavirus viruses. It can undergo an enzyme-independent self-cleavage at its own C-terminus during protein translation, enabling the ribosome skipping to the next codon to continue the translation [24-26]. By assembling a $\beta$-mannanase M330 gene and a $\beta$-xylanase Xyn-CDBFV gene into a single ORF with the FMDV P2A [27], the efficiency of P2A self-cleavage in secretory expression of multiple enzymes in $K$. marxianus was evaluated. Subsequently, three hemicellulolytic enzymes were secreted coordinately using the FMDV P2A. In HSFs of corncobs, saccharification and ethanol production were improved when using the engineered strain as a fermentation starter. Our findings demonstrate that the 2A-mediated ribosomes skipping is a good tool for secretory co-expression of multiple enzymes in $K$. marxianus, which is greatly beneficial to the construction of CBP strains for cellulosic ethanol production.

\section{Results and discussion}

\section{Self-cleavage of polyprotein with FMDV P2A in $K$.}

\section{marxianus}

Due to the chemical diversity of hemicellulose structure that heterogeneous polysaccharides with both linear and branched molecules are cross-linked to cellulose microfibrils, complete degradation requires multiple hemicellulases to act synergically [28]. Aiming to facilely express multiple enzymes in ethanologenic $K$. marxianus for the hemicellulose degradation, we resorted to a $2 \mathrm{~A}$-mediated ribosome skipping for co-translational cleavage of the polyprotein. In eukaryotic cells, the 2A-mediated cleavage is a common phenomenon that it skips the glycyl-prolyl peptide bond synthesis at the C-terminus of $2 \mathrm{~A}$, releases the nascent protein, and resumes the downstream translation [29]. While the 2A self-cleavage efficiency strongly relies on the sequence contexts of upstream and downstream ORFs in the polycistrons [30]. Given that we first tested the efficiency of FMDV P2A self-cleaving in $K$. marxianus by expression of three polycistronic genes $I M X, I M P X$, and $I M P \alpha X$ (Fig. 1a, b). The $I M X$ gene consisted of an M330 coding sequence (INU1 signal peptide + mature protein coding sequence) and a C-terminal 6xHis-tagged Xyn-CDBFV mature protein coding sequence fused in-frame directly. In the $I M P X$ gene, the P2A sequence was incorporated between M330 and Xyn-CDBFV without a stop codon. The $I M P \alpha X$ gene had an extra $\alpha$-factor signal sequence between and XynCDBFV besides the P2A sequence. These three polycistronic genes were cloned into the vector pUKDN132, respectively, in which their expressions were all driven by an INU1 promoter from K. marxianus.

After cultured in flasks, expressions of M330 and Xyn-CDBFV were detected by measuring the activities of $\beta$-mannanase and $\beta$-xylanase in both supernatants and cell lysates of the IMX, IMPX, and IMP $\alpha$ X strains, obtained by transforming with the plasmids pUKDN132/ IMX, pUKDN132/IMPX, and pUKDN132/IMP $\alpha$ X, respectively. Unexpectedly, the IMX strain, as a control, produced high activities of both $\beta$-mannanase and $\beta$-xylanase in the supernatant, with approximately 24.03 and $155.26 \mathrm{U} / \mathrm{mL}$ respectively (Table 1 ). This result suggested that M330 and Xyn-CDBFV fused directly did not impair their catalytic activities, and its double activities provided a good reference to assessing the effect of P2A on the expression of downstream Xyn-CDBFV. Extracellular $\beta$-mannanase activities of the IMPX and IMP $\alpha \mathrm{X}$ strains were about 21.34 and $15.50 \mathrm{U} / \mathrm{mL}$, respectively, which were slightly lower than that of the IMX strain. Instead, their intracellular $\beta$-mannanase activities were higher than that of the control strain, inferring that fusion of Xyn-CDBFV to the C-terminus of M330 with P2A slightly decreased the secretory expression of M330.

In our constructs, the efficiency of FMDV P2A selfcleavage was closely associated with the production of Xyn-CDBFV. The IMP $\alpha$ X strains secreted $136.17 \mathrm{U} / \mathrm{mL}$ $\beta$-xylanase into the supernatants, but retained $39.43 \mathrm{U} /$ $\mathrm{mL}$ intracellularly. By contrast, the $\beta$-xylanase activity in the supernatant of the IMPX strain was $42.07 \mathrm{U} / \mathrm{mL}$, which was far less than the intracellular activity $87.59 \mathrm{U} /$ $\mathrm{mL}$. To confirm whether the $\beta$-xylanase activities of both IMPX and IMP $\alpha$ X strains were the self-cleavaged XynCDBFV by the 2A-mediated ribosomes skipping during translation, these samples were further analyzed by SDS-PAGE and western blot. As shown in Fig. 1c, e, there 


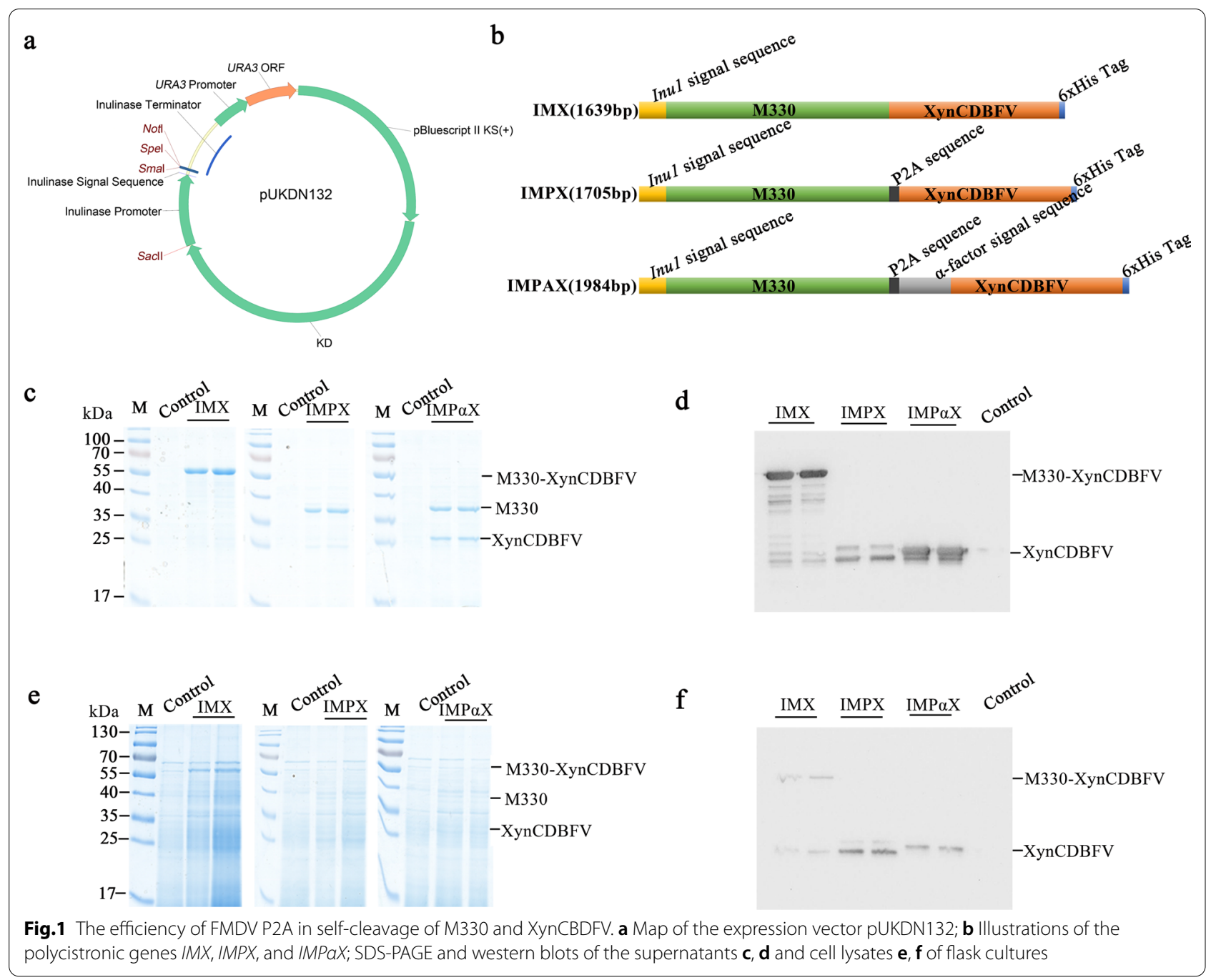

Table 1 The $\beta$-mannanase and $\beta$-xylanase activities of the IMX, IMPX, and IMPaX strains cultured in flasks at $30{ }^{\circ} \mathrm{C}, 220 \mathrm{rpm}$ for $72 \mathrm{~h}$

\begin{tabular}{lllllll}
\hline Strains & \multicolumn{2}{l}{$\beta$-Mannanase activities } & & \multicolumn{2}{l}{$\beta$-Xylanase activities } \\
\cline { 2 - 3 } \cline { 6 - 7 } & Extracellular & Intracellular & & Extracellular & Intracellular \\
\hline IMX & $24.03 \pm 3.74$ & $1.13 \pm 0.19$ & & $155.26 \pm 4.24$ & $44.17 \pm 4.24$ \\
IMPX & $21.34 \pm 1.37$ & $4.50 \pm 0.75$ & & $42.07 \pm 4.99$ & $87.59 \pm 11.41$ \\
IMPaX & $15.50 \pm 1.91$ & $4.62 \pm 0.44$ & & $136.17 \pm 15.34$ & $39.43 \pm 4.11$ \\
\hline
\end{tabular}

was a protein band with approximate $57 \mathrm{kDa}$ molecular weight in the supernatants of IMX strain, which was in accordance with the theoretical prediction of the fused IMX protein. In both supernatants of the IMP $\alpha \mathrm{X}$ and IMPX strains, M330 and Xyn-CDBFV were secreted alone, but the secretory Xyn-CDBFV of the IMP $\alpha$ X strain was much higher than that of the IMPX strain, suggesting that, in the presence of P2A and $\alpha$-factor signal sequence, Xyn-CDBFV could be secreted to medium more efficiently. This result was in agreement with the previous literature [31]. Furthermore, western blot assays for the His-tagged Xyn-CDBFV in the above samples were in compliance with the enzymatic assays and SDS-PAGE above (Fig. 1d and f). Nevertheless, to extracellularly express two proteins via FMDV P2A self-cleavage, an extra signal sequence should be included at the N-terminus of the downstream gene. Compared with the internal ribosomal entry site (IRES), which is first identified in encephalomyocarditis virus, the 2A-mediated ribosomal 'skipping' is more attractive as it can express multiple cistrons at equimolar levels theoretically [32]. However, it slightly decreased the total level of expressed proteins, especially for the downstream one. This is likely due to the long length of the IMP $\alpha X$ gene because gene length is an important regulator for ribosome recruitment and protein synthesis [33]. In S. cerevisiae, a 'long' gene 
increased even with a $0.3 \mathrm{~kb}$ fragment reduces its transcription clearly [34].

\section{Coexpression of hemicellulolytic enzymes with FMDV P2A}

Hemicellulose acts as one important factor contributing to the recalcitrance of lignocellulose, and they, even in low quantities, can prevent cellulases to degrade cellulose efficiently [35]. Cellulase supplemented with endoxylanase promotes the hydrolysis of steam-exploded feed stocks, releases more glucose, accumulates higher content of xylobiose and xylo-oligosaccharides [36, 37]. Xylose yield, however, was not significantly elevated, which may be due to the insufficient $\beta$-xylosidase in most cellulase enzymes produced by filamentous fungi $T$. reesei $[38,39]$. Presumably, an ethanologenic strain that coexpresses multiple hemicellulases, especially $\beta$-xylanase and $\beta$-xylosidase, is able to eliminate the accumulation of xylo-oligosaccharides and produce more fermentable xylose. To test that, a $\beta$-xylosidase RuXyn1 with a high capability of xylose conversion from intermediate xylo-oligosaccharides was applied to co-express with $\beta$-xylanase in $K$. marxianus [40]. The RuXyn1 coding sequence was fused to Xyn-CDBFV with a P2A and an $\alpha$-factor signal sequence (Fig. $2 \mathrm{a}$ ), and then the resulting IXP $\alpha \mathrm{R}$ was expressed in $K$. marxianus under the unique INU1 promoter. The IXP $\alpha \mathrm{R}$ strain transformed with the
pUKDN132/IXP $\alpha$ R produced 59.01 and $0.05 \mathrm{U} / \mathrm{mL}$ of extracellular $\beta$-xylanase and $\beta$-xylosidase in flask cultures that were grown in YG mediums at $30{ }^{\circ} \mathrm{C}, 220 \mathrm{rpm}$ for $72 \mathrm{~h}$, respectively (Fig. $2 \mathrm{~b}-\mathrm{d}$ ).

Supplements of $\beta$-mannanase facilitated the total enzymatic hydrolysis of lignocellulose feedstock and brewery's by-product, such as beech sawdust, spruce, Douglas fir wood and chips spent grain [41-44]. Given the critical roles of $\beta$-mannanase, $\beta$-xylanase and $\beta$-xylosidase in the hydrolysis of lignocellulose, the feasibility of P2A for coordinately expressing three selected enzymes in one ORF was further tested. A polycistronic gene $I M P \alpha X P \alpha R$ compacted M330, Xyn-CDBFV and RuXyn1 into one ORF was constructed, each with a signal sequence (Fig. 2a). Consistent with the IMP $\alpha$ X and IXP $\alpha$ R strains, activities for all three enzymes were detectable in the crude supernatant of the IMP $\alpha \mathrm{XP} \alpha \mathrm{R}$ strain obtained by transformation of the pUKDN132/IMP $\alpha$ XP $\alpha$ R plasmid. Specifically, the activities of $\beta$-mannanase, $\beta$-xylanase and $\beta$-xylosidase were $18.90,61.00$, and $0.07 \mathrm{U} / \mathrm{mL}$, respectively, after culture in YG mediums at $30{ }^{\circ} \mathrm{C}, 220 \mathrm{rpm}$ for $72 \mathrm{~h}$ (Fig. 2c-e). As expected, Fig. 2b showed three protein bands in the culture supernatant of the IMP $\alpha \mathrm{XP} \alpha \mathrm{R}$ strain corresponding to the predicted molecular weights of M330, Xyn-CDBFV and RuXyn1, which confirmed

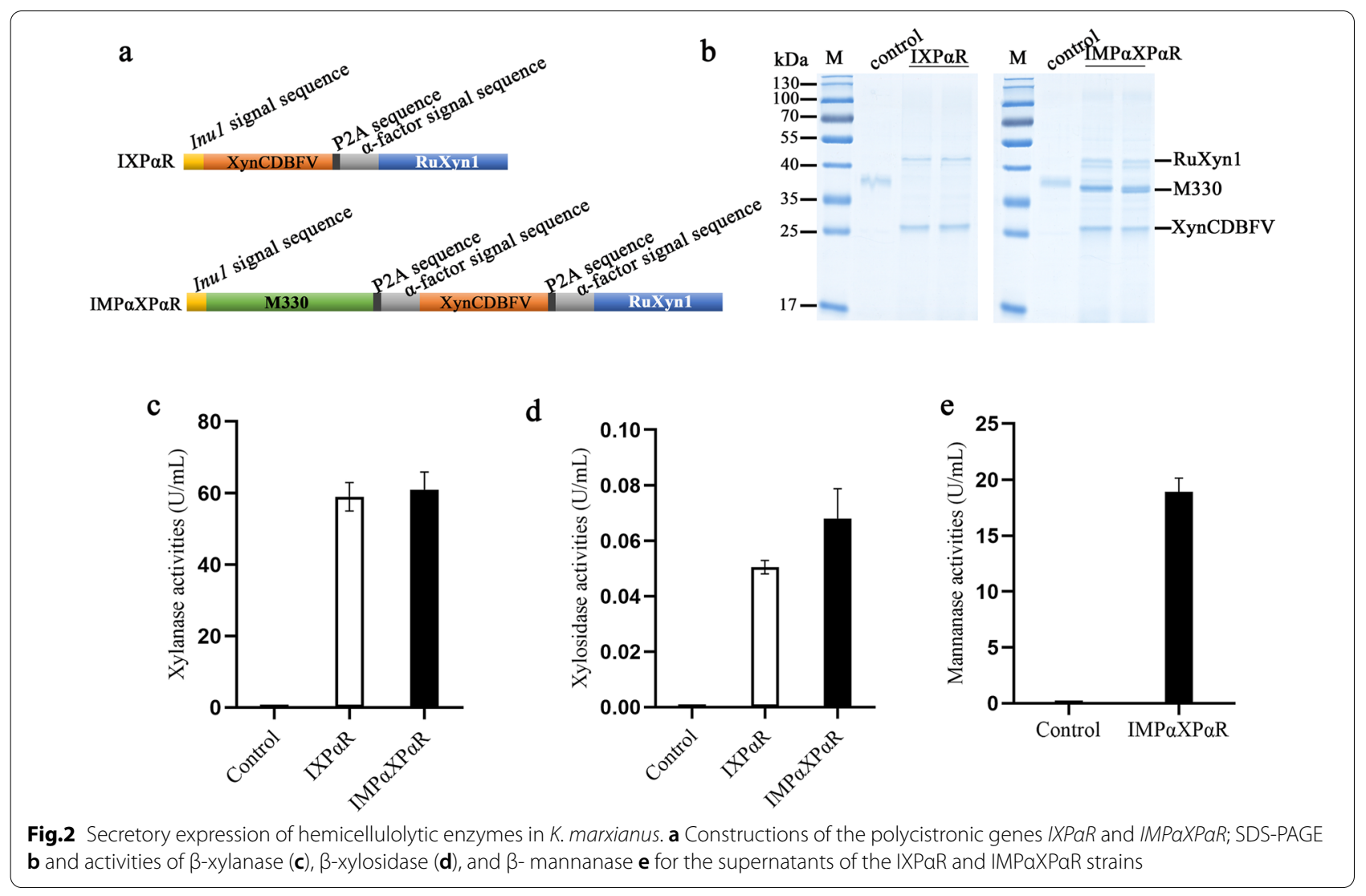


that FMDV P2A was applicable for secretory co-expression of multiple enzymes in K. marxianus.

\section{Preparation of hemicellulolase mixtures by recombinant $K$. marxianus strains}

We have previously developed a high-cell density fedbatch fermentation for single hemicellulolytic enzyme production in $K$. marxianus [18]. In this study, the productions of multiple enzymes in fed-batch fermentation for both the IXP $\alpha$ R and IMP $\alpha X P \alpha R$ strains were also evaluated. $K$. marxianus is a Crabtree-negative yeast that does not perform aerobic alcoholic fermentation, but can respire even in high glucose concentrations [45]. However, high glucose concentration adversely causes respiratory repression and turn to alcoholic fermentation especially in high-cell density, probably due to the insufficient oxygen supply. Similar to S. cerevisiae, a Crabtree positive yeast that predominantly produces ethanol in high glucose even in sufficient oxygen levels, it is practicable to guide $K$. marxianus to utilize glucose for respiratory metabolism and convert carbon resources into cell biomass, as glucose can be fed slowly to maintain a concentration below the threshold value in fed-batch fermentation [46, 47]. Additionally, ethanol fermentation could affect the cell growth of $K$. marxianus, thus decreasing the expression of heterologous proteins. To circumvent this, we controlled the dissolved $\mathrm{O}_{2}$ above $10 \%$ by limiting the fed rate of glucose during fermentation. The cell densities of both strains reached more than $450\left(\mathrm{OD}_{600 \mathrm{~nm}}\right)$ after $48 \mathrm{~h}$ (Fig. 3a). It seemed that the production of secretory proteins synchronized with the cell growth, as all enzymes were dramatically accumulated during the stage from 16 to $48 \mathrm{~h}$ (Fig. 3b-d). After $72 \mathrm{~h}$, the IXP $\alpha$ R strain secreted $1664.2 \mathrm{U} / \mathrm{mL}$ of $1 \beta$-xylanase and $0.90 \mathrm{U} / \mathrm{L} \beta$-xylosidase, which were about 28 and 18 folds that of in the flask cultures respectively. SDS-PAGE showed that the IXP $\alpha R$ strain secreted two different protein bands that were the mature forms of Xyn-CDBFV and RuXyn1. The IMP $\alpha$ XP $\alpha \mathrm{R}$ strain produced $2210.5 \mathrm{U} /$ $\mathrm{mL}$ of $\beta$-xylanase and $1.25 \mathrm{U} / \mathrm{mL}$ of $\beta$-xylosidase, slightly higher than that of the IXP $\alpha$ R strain. As well, this strain also produced $159.8 \mathrm{U} / \mathrm{mL}$ of $\beta$-mannanase concurrently, and all enzymes were secreted extracellularly as their mature forms (Fig. 3e, f).

\section{Enzymatic hydrolyses of pretreated corncobs}

Hemicellulases acted with cellulase significantly enhance the hydrolysis of lignocellulose [48, 49]. The performances of the prepared hemicellulase cocktails on the promotion of lignocellulose hydrolyses were evaluated next using corncob as a feedstock for the enzymatic hydrolyses, because it is one of the most abundant inedible agricultural residues and consists of relatively high content of hemicellulose ( 40\%) [50]. Enzymatic hydrolyses were conducted with $10 \%(\mathrm{w} / \mathrm{v})$ corncobs pretreated by aqueous dilute acid, and 5 FPU of Cellic ${ }^{\circledR}$ CTec 2 cellulase per gram solids. After $96 \mathrm{~h}$, about $405.6 \mathrm{mM}$ soluble sugars were released from the pretreated corncobs by Cellic ${ }^{\circledR}$ CTec 2 alone. To test the $\beta$-xylanase XynCDBFV and $\beta$-xylosidase RuXy1 performances on the enzymatic hydrolyses, $300 \mu \mathrm{l}$ of supernatant collected from the IXP $\alpha \mathrm{R}$ strain fed-batch culture at $48 \mathrm{~h}$, equal to $172.7 \mathrm{U} \beta$-xylanase and $0.129 \mathrm{U} \beta$-xylosidase quantified at $30{ }^{\circ} \mathrm{C}$, was supplemented to the Cellic ${ }^{\circledR} \mathrm{CTec} 2$ cellulase. In accord with previous literatures on pine kraft pulp and softwood [42, 51], supplementations of xylanolytic enzymes to the Cellic ${ }^{\circledR}$ CTec2 cellulase improved the enzymatic hydrolysis of corncobs. At each sampling point, the addition of the enzymes produced by the IXP $\alpha$ R strain generated higher contents of soluble sugars. After hydrolysis for $96 \mathrm{~h}$, soluble sugars increased by $15.7 \%$ compared to the Cellic ${ }^{\circledR}$ CTec2 cellulase alone (Fig. 4a). Similarly, the amounts of monomeric glucose and xylose increased to 61.39 and $8.32 \mathrm{~g} / \mathrm{L}$, respectively, which were 11.2 and $11.1 \%$ higher than that of Cellic ${ }^{\circledR}$ CTec2 cellulase alone (Fig. 4b, c).

The role of $\beta$-mannanase M330 for the corncob hydrolysis was also evaluated in combination with $\beta$-xylanase and $\beta$-xylosidase. The culture supernatant of IMP $\alpha \mathrm{XP} \alpha \mathrm{R}$ strain containing $8.91 \mathrm{U} \quad \beta$-mannanase, $157.85 \mathrm{U}$ $\beta$-xylanase, and $0.164 \mathrm{U} \beta$-xylosidase quantified at 30 ${ }^{\circ} \mathrm{C}$ was supplemented to the Cellic ${ }^{\circledR} \mathrm{CTec} 2$ cellulase. As shown in Fig. 4a, the amounts of total soluble sugars were increased over time by the supplementary $\beta$-mannanase. At $96 \mathrm{~h}$, about $12.1 \%$ more soluble sugars were obtained comparing to that of the IXP $\alpha$ R strain. The glucose and xylose contents were increased to 65.48 and $8.45 \mathrm{~g} / \mathrm{L}$ (Fig. 4b, c), which were $11.9 \%$ and $11.4 \%$ higher than that of the xylanolytic enzymes respectively, showing that $\beta$-mannanase could facilitate a more extensive breakdown of corncobs. This promotion may be ascribed to the deep hydrolysis glucomannan by the synergistic action of $\beta$-mannanase with endoglucanase $\operatorname{TrCel} 5 \mathrm{~A}$ of $T$. reesei presented in Cellic ${ }^{\circledR} \mathrm{CTec} 2$, a crude cellulase produced by the ascomycete fungus $T$. reesei, since TrCel5A has minor hydrolytic activity towards glucomannans [42].

\section{HSFs of ethanol from pretreated corncobs}

Besides applications in the expression of heterologous proteins, the K. marxianus strain used in this study can produce ethanol from multiple substrates, including glucose, xylose, lactose, and inulin, with a maximum ethanol concentration higher than $100 \mathrm{~g} / \mathrm{L}[52,53]$. Enzymatic hydrolyses of the pretreated corncobs indicated that hemicellulolases expressed by the IMP $\alpha \mathrm{XP} \alpha \mathrm{R}$ strain would be conducive to ethanol production from 


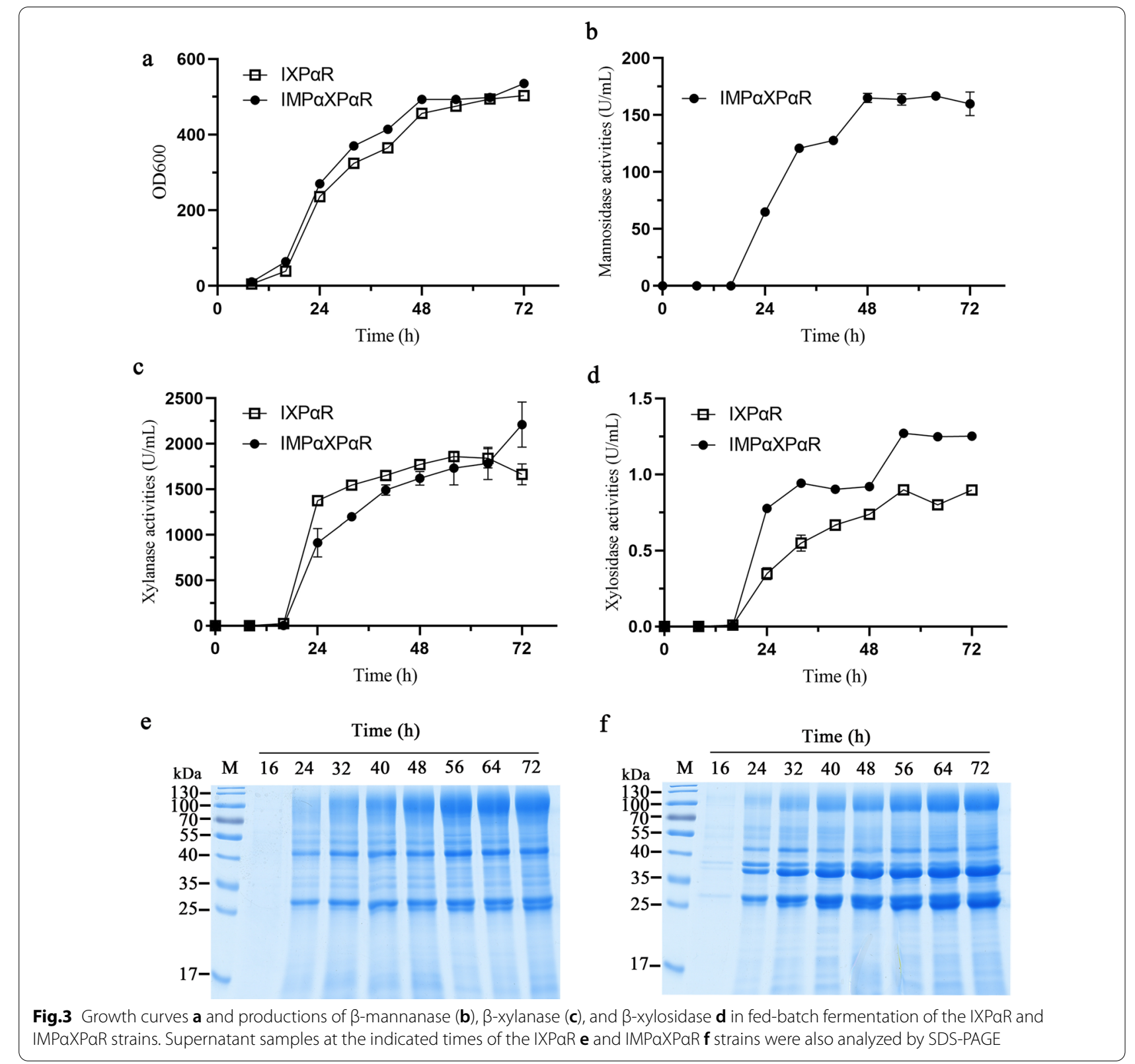

pretreated lignocellulosic biomass. Subsequently, we evaluated the potential of recombinant IMP $\alpha \mathrm{XP} \alpha \mathrm{R}$ strain as a fermentation starter to produce ethanol from both the DAP and AAP corncobs. HSFs were performed by pre-hydrolyzing pretreated corncobs with $10 \mathrm{FPU}$ commercial cellulase per gram solids at a solid-to-liquid (S/L) ratio of 1:10 (irrespective of the moisture content) for $72 \mathrm{~h}$ before being inoculated with the IMP $\alpha \mathrm{XP} \alpha \mathrm{R}$ or FIM-1 (control) strain. Considering that $K$. marxianus is more strictly Crabtree negative than the model organism species Kluyveromyces lactis and other known Crabtreenegative yeasts, it cannot grow under strictly anaerobic conditions and its ethanol fermentation exclusively relies on oxygen limitation [16]. As described previously, dissolved oxygen tension is a key factor for the production of inulinase in $K$. marxianus [54, 55]. In this study, expressions of the hemicellulolytic enzymes in the IMP $\alpha \mathrm{XP} \alpha \mathrm{R}$ strain were samely driven by the inulinase promoter. To ensure that the hemicellulolytic enzymes were highly expressed and sufficient for HSFs, HSFs starters were prepared by high-cell-density fed-batch culture in $5 \mathrm{~L}$ fermenters under aeration and agitation. In addition, the effect of the pretreatment mode on the structure and composition of corncobs were also taken into account 

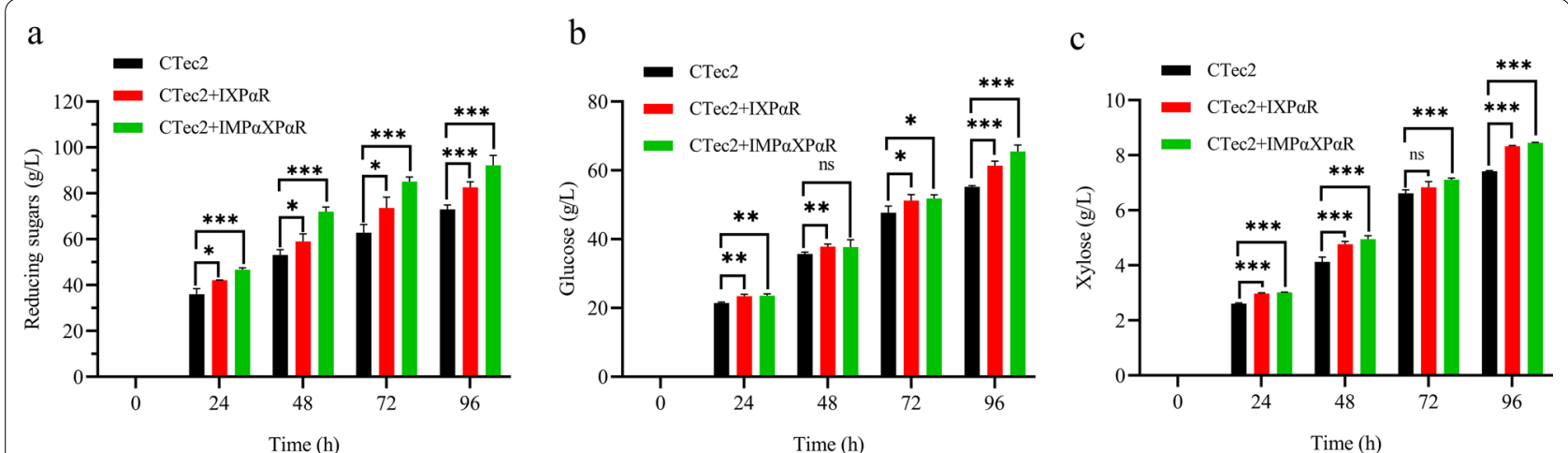

Fig.4 Concentrations of the reducing sugars $(\mathbf{a})$, glucose $(\mathbf{b})$, and xylose $(\mathbf{c})$ over time in the hydrolysis of DAP corncobs. The statistical differences were analyzed using the t-test. ${ }^{*} P<0.05 ;{ }^{* *} P<0.01 ;{ }^{* * *} P<0.001$

[56], since it may affect the performance of IMP $\alpha X P \alpha R$ strain in HSFs. Accordingly, corncobs pretreated by the diluted acid and aqueous ammonia, containing 57.4 and $48.9 \%$ of glucan, and 8.2 and $32.1 \%$ of xylan, respectively, were both used for HSFs.

After prehydrolysis with Cellic $^{\circledR}$ CTec2 for $72 \mathrm{~h}$, about $80 \%$ glucan and $84 \%$ xylan of DAP corncobs were degraded into monosaccharides, liberating $48.5 \mathrm{~g} / \mathrm{L}$ glucose and $7.2 \mathrm{~g} / \mathrm{L}$ xylose. Ethanolic fermentation was started by inoculating the cell cultures of the IMP $\alpha X P \alpha R$ or control strains prepared by fed-batch fermentation. As shown in Fig. 5a, contents of glucose and xylose in HSFs with IMP $\alpha X P \alpha R$ strain were slightly higher than with FIM-1 strain during the first $72 \mathrm{~h}$ when using the DAP corncobs. This was in agreement with the enzymatic saccharification described above. Besides, ethanol yields by the IMP $\alpha \mathrm{XP} \alpha \mathrm{R}$ strain during the same time were slightly higher than the control as well. After $144 \mathrm{~h}$, the ethanol concentration in HSF with the IMP $\alpha \mathrm{XP} \alpha \mathrm{R}$ strain was $16.4 \mathrm{~g} / \mathrm{L}$, and it was about $8.7 \%$ higher than the control $15.1 \mathrm{~g} / \mathrm{L}$. In the case of xylitol production, there was no significantly difference between the IMP $\alpha$ XP $\alpha$ R HSFs and the control, since its concentrations were very low in all HSFs, which was below $1 \mathrm{~g} / \mathrm{L}$ even after $240 \mathrm{~h}$ fermentation. Probably, it was due to the strong repression of xylose utilization by glucose in simultaneous fermentation of them with K. marxianus [57].

But in the case of AAP corncobs, only $60-70 \%$ glucan and $62-67 \%$ xylan were hydrolyzed by Ctec2 before HSFs. Due to lower saccharification of AAP corncobs by the Cellic ${ }^{\circledR}$ CTec 2 cellulase, both glucose and xylose contents in the samples for IMP $\alpha$ XP $\alpha$ R HSFs were lower than those in control, which were 26.4 and $17.9 \mathrm{~g} / \mathrm{L}$, and 30.9 and $19.4 \mathrm{~g} / \mathrm{L}$, respectively. Inevitably, during the preceding $48 \mathrm{~h}$ of HSFs, both glucose and xylose contents in the IMP $\alpha \mathrm{XP} \alpha \mathrm{R}$ HSFs were lower than in the control
(Fig. 5b). However, their contents in the IMP $\alpha X P \alpha R$ HSFs became apparently higher than in the control at $72 \mathrm{~h}$, as there were $3.3 \mathrm{~g} / \mathrm{L}$ of glucose and $16.9 \mathrm{~g} / \mathrm{L}$ of xylose in the IMP $\alpha \mathrm{XP} \alpha \mathrm{R}$ HSFs, and $1.68 \mathrm{~g} / \mathrm{L}$ of glucose and $15.0 \mathrm{~g} / \mathrm{L}$ of xylose in the control, respectively. After $120 \mathrm{~h}$, glucose was depleted in all HSFs, but the xylose content in the IMP $\alpha$ XP $\alpha$ R HSFs was still $17.5 \mathrm{~g} / \mathrm{L}$, which was $18.2 \%$ higher than in the control $(p<0.01)$. The reason for this was that $K$. marxianus cannot assimilate xylose to form ethanol under anaerobic condition [58]. Similarly, ethanol yield in the IMP $\alpha X P \alpha R$ HSFs was $14.2 \mathrm{~g} / \mathrm{L}$ at this time point, which was $12.7 \%$ higher than that of the control $(p<0.05)$. Before $144 \mathrm{~h}$, xylitol yield by the IMP $\alpha$ XP $\alpha$ R strain was not different from the control. These results indicated that the hemicellulolytic enzymes of the IMP $\alpha X P \alpha R$ strain improved the hydrolysis and ethanol production in HSFs of pretreated corncobs, especially with high xylan content of feedstocks.

Comparing with HSFs of DAP corncobs, glucose consumption rate was in apparent higher when using AAP corncobs. Additionally, xylose was consumed to form xylitol by both strains before $48 \mathrm{~h}$ in HSFs of AAP corncobs, while its consumption did not occur until $144 \mathrm{~h}$ in HSFs of DAP corncobs. A recent study demonstrated that the addition of nitrogen increased the fermentative capacity of $K$. marxianus during ethanol production [59]. Thus, the residual ammonia in AAP corncobs might be the critical foctor that was conducive to the glucose uptake and ethanol production and turned to affect the xylose utilization. As an inexpensive and renewable resource in the world, corncob has been commonly explored as feedstocks for the productions of xylitol, bioethanol, butanol, fatty acids, and other chemicals $[50,60]$. However, nitrogen-dependent anaerobic bioethanol fermentation with $K$. marxianus is not fit to the pretreated corncobs with a very high rate of $\mathrm{C} / \mathrm{N}$. 

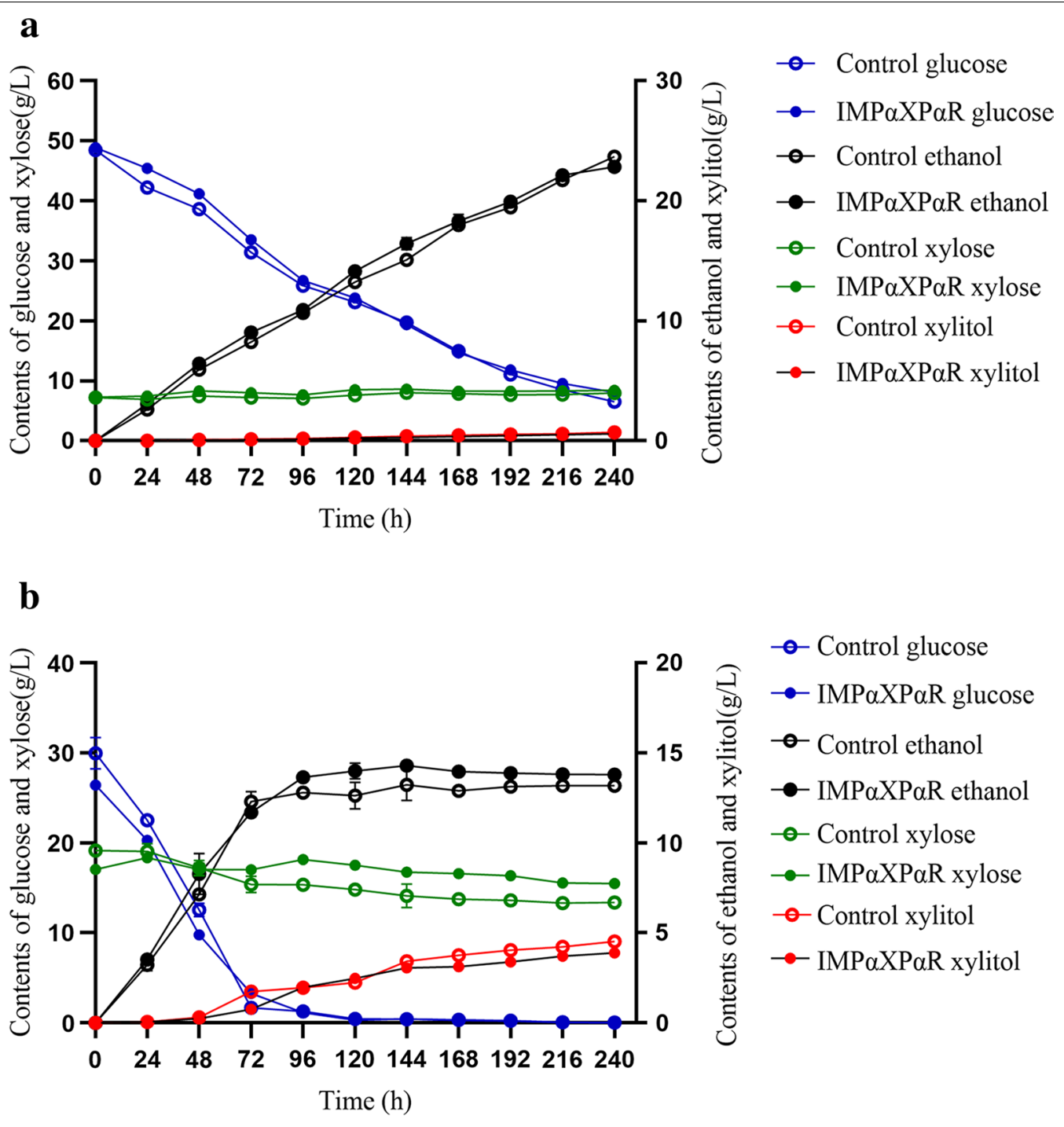

Fig.5 Profiles of glucose, xylose, ethanol, and xylitol in HSFs of the diluted acid $\mathbf{a}$ and aqueous ammonia $\mathbf{b}$ pretreated corncobs

Fortunately, municipal wastewater containing very low $\mathrm{C} / \mathrm{N}$, with $10-100 \mathrm{mg} / \mathrm{L}$ of total nitrogen, may offset the nitrogen gap of $K$. marxianus during anaerobic fermentation, which is beneficial for lower biofuel production costs and biological nitrogen removal [61].

\section{Conclusions}

In this study, we used a 2A-mediated ribosome skipping strategy to coordinately express hemicellulolytic enzymes in $K$. marxianus, and investigated the performances of the multiple expressed enzymes in saccharification and ethanol production from pretreated corncobs. The FMDV P2A showed high efficiency in secretory co-expression of multiple enzymes in $K$. marxianus, and that three hemicellulolytic enzymes, including a $\beta$-mannanase M330, a $\beta$-xylanase Xyn-CDBFV, and $\beta$-xylosidase RuXyn 1 , were coordinately secreted in the IMP $\alpha X P \alpha$ strain. Multiple enzymes of the recombinant $K$. marxianus strains increased both glucose and xylose yields from DAP corncobs when acted with the commercial cellulases, indicating that strengthening of the hemicellulolytic activity could improve the enzymatic saccharification of lignocellulose. Considering the effect of oxygen limitation on the expression of multiple enzymes in $K$. marxianus during ethanol fermentation, as well as a compromise of ethanol productivity with enzyme productions, HSFs of pretreated corncobs were conducted using fed-batch cultures grown under aeration and agitation. Ethanol yield in HSF of DAP corncobs with the IMP $\alpha$ XP $\alpha$ R strain was about $8.7 \%$ higher than 
the control, while it was $12.7 \%$ higher when using AAP corncobs. When using DAP corncobs, there was no significant difference in the productions of xylose along with xylitol between the IMP $\alpha \mathrm{XP} \alpha \mathrm{R}$ and control strain. By contrast, in HSFs of AAP corncobs containing a higher content of xylan, the xylose yield in the IMP $\alpha$ XP $\alpha$ R HSFs was $18.2 \%$ higher than in the control at $120 \mathrm{~h}$, suggesting that promotions on ethanol and xylose yields in HSFs by hemicellulases were closed to the content of hemicellulose in feedstocks. Our findings demonstrate that the 2A-mediated ribosome skipping is a good tool for secretory co-expression of multiple enzymes in K. marxianus, which is greatly beneficial to the construction of CBP strains for cellulosic ethanol production.

\section{Methods}

\section{Strains and plasmids}

The $K$. marxianus Fim-1 $\triangle U R A 3$ is a uracil auxotrophic strain derived from the FIM-1 strain that has been deposited in China General Microbiological Culture Collection Center (CGMCC No.10621). The expression plasmid pUKDN132 was constructed as described previously [18].

\section{Expression plasmids constructions and transformations}

A polycistronic gene M330-Xyn-CDBFV (hereafter termed the IMX gene) that a $\beta$-xylanase (EC 3.2.1.8) gene $X y n-C D B F V$ from Neocallimastix patriciarum was directly fused to the $C$-terminus of $\beta$-mannanase (EC. 3.2.1.78) gene M330 from Bacillus sp. N16-5 was constructed as described below. The M330 gene was amplified from the pZP41plasmid by the primers MF and IMXR1 (Table 2), and the Xyn-CDBFV gene was amplified with IMXF and XR from a pET21a/Xyn-CDBFV [62]. After purification with a SanPrep Column DNA Gel Extraction Kit (B518131, Sangon Biotech, Shanghai, China), the two PCR fragments were ligated together by Gibson assembly [63], and then used as a template to amplify the fused hybrid gene $I M X$ with the primers MF and XR. The resulting PCR amplicon was ligated with the SpeI and NotI linearized pUKDN132 by Gibson assembly, and generated the plasmid pUKDN132/IMX.

Two polycistronic genes, IMPX and $I M P \alpha X$, that contained a P2A sequence between $M 330$ and Xyn-CDBFV alone or with an $\alpha$-factor signal sequence from $S$. cerevisiae were also constructed. The $P 2 A$ sequence was added to the 3' terminus of $M 330$ by PCR using the primers MF and IMPR. The $X y n-C D B F V$ sequence was amplified by the primer pair IMPXF/XR, and ligated with the $P 2 A$ fused M330. After that, the full-length IMPX was amplified by the primers MF and XR, and then inserted into the pUKDN132, obtaining the pUKDN132/IMPX plasmid. When assembling the IMP $\alpha X$ gene, the $\alpha$-factor signal sequence was amplified from the plasmid pPIC9 (Invitrogen, USA) using the primers $\mathrm{P} \alpha \mathrm{F} 1$ and $\alpha \mathrm{XR} 1$, and the $X y n-C D B F V$ sequence was amplified by the primers $\alpha X F 1$ and XR from the pET21a/Xyn-CDBFV. Three fragments including the $P 2 A$ fused $M 330, \alpha$-factor signal sequence, and $X y n-C D B F V$ were ligated together to assemble the polycistronic gene IMP $\alpha X$ as described above. After cloned into pUKDN132, the resulting plasmid was then termed as pUKDN132/IMP $\alpha$ X.

The polycistronic $I M P \alpha X P \alpha R$ gene integrated three genes into a single ORF was constructed by assembling the IMP $\alpha X$ gene lack of the stop codon TAG, a

Table2 Primer sequences used in this work

\begin{tabular}{ll}
\hline Primers & Sequences \\
\hline MF & ATGAAGTTAGCATACTCCCTCTTGC \\
IMXR1 & GAACTACAGAACTTTGTGTAAATACGGTGGATGGTTTGGAG \\
IMXF & TCCACCGTATTACACAAAGTTTCTGTAGTTCAGCTTCTC \\
IMPR & CTAGTGATGATGATGATGGTGATCACCAATGTAAACCTTTGCGTATGG \\
IMPXF & AGGACCGGGGTTTCTTCCACGTCTCCTGCTTGCTTTAACAGAGAGAAGT \\
PaF1 & TCGTGGCTCCGGATCCTGTAAATACGGTGATGGTTGGA \\
aXR1 & TGGAAGAAAACCCCGGTCCTCAAAGTTCTGTAGTTCAGCTTCTCACT \\
aXF1 & GGAAGAAACCCCGGTCCTATGAGATTTCCTTCAATTTTTACTGCAG \\
XPR & GAGAAGCTGAACTACAGAAACTTTGCCCGGGTACGTAAGCTTCAGCCTCT \\
XPaF & AGAGGCTGAAGCTTACGTACCCGGGCAAAGTTTCTGTAGTTCAGCTTCTC \\
aR1 & ATCACCAATGTAAACCTTTGCGTATG \\
aRF & ACGCAAAGGTTACATTGGTGATGGATCCGGAGCCACGAACTTCTCTC \\
RR & ATAGCGTTTCTAAACTTTATCAGCCCCGGGACGTAAGCTTCAGCCTCT \\
IXF & TGATAAAGTAAAAAACGCTAT \\
\hline
\end{tabular}


$P 2 A$-linked $\alpha$-factor signal sequence and a $\beta$-xylosidase (EC.3.2.1.37) gene RuXyn1 from uncultured Yak rumen microorganism. The IMP $\alpha X$ fragment and the $P 2 A$ linked $\alpha$-factor signal sequence were amplified from pUKDN132/IMP $\alpha \mathrm{X}$ by the primer pairs, MF/XPR and $\mathrm{XP} \alpha \mathrm{F} / \alpha \mathrm{R} 1$, respectively, while the $R u X y n 1$ fragment was amplified from a pET21/RuXyn1 vector using the primers $\alpha R F$ and RR [40]. Three fragments were ligated by Gibson assembly to get the full length of IMP $\alpha X P \alpha R$. After PCR amplification with the primers MF and $\mathrm{RR}$, the IMP $\alpha X P \alpha R$ was inserted into the SpeI/Not I site of pUKDN132 to obtain the plasmid pUKDN132/ IMP $\alpha X P \alpha R$. The plasmid pUKDN132/IXP $\alpha R$ was constructed by inserting the XP $\alpha \mathrm{R}$ fragment, amplified from pUKDN132/IMP $\alpha$ XP $\alpha$ R by the primers IXF and RR, into the SpeI/NotI site of pUKDN132.

For plasmid transformations, the K. marxianus Fim$1 \triangle U R A 3$ was inoculated in $5 \mathrm{ml}$ YPD medium (1\% Yeast Extract, 2\% Peptone, 2\% Glucose, pH 6.5), and cultured at $30{ }^{\circ} \mathrm{C}, 220 \mathrm{rpm}$ for $20 \mathrm{~h}$. Yeast cells were collected by centrifugation, and all plasmid transformations were conducted according to the method by Antunes et al. [64]. Transformants were then selected on synthetic defined (SD) plates (pH 5.5) containing $0.67 \%$ yeast nitrogen base without amino acids (YNB), $2 \%$ glucose, and $2 \%$ agar.

\section{Enzymatic assays}

The activity of $\beta$-mannanase was determined with $0.5 \%$ locust bean gum (G0753, Sigma-Aldrich, USA) in $50 \mathrm{mM}$ acetate buffer $\mathrm{pH} 5.5$ at $68^{\circ} \mathrm{C}$ [65]. Quantitative assays of $\beta$-xylanase were performed using $1 \%$ wheat arabinoxylan (P-WAXYL, Megazyme, Bray, Ireland) buffered with $50 \mathrm{mM}$ acetate $\mathrm{pH} 5.5$ at $50{ }^{\circ} \mathrm{C}$ [62]. $\beta$-xylosidase activities were measured using $p$-nitrophenyl- $\beta$-D-xylopyranoside as we described previously [40]. One unit (U) of enzyme activity was defined as the amount of enzyme releasing $1 \mu \mathrm{mol}$ of reducing sugars or $p$-nitrophenol per minute.

\section{Western blot assays}

Transformants were grown in YG mediums ( $2 \%$ yeast extract, $4 \%$ glucose, $\mathrm{pH} 6.0$ ) at $30{ }^{\circ} \mathrm{C}, 220 \mathrm{rpm}$ for $72 \mathrm{~h}$. One milliliter of cultures was harvested and centrifuged for $10 \mathrm{~min}$ at $5000 \mathrm{rpm}$ to detect the secretory or intracellular expression of enzymes by western blot. To prepare lysate samples, cells were suspended in $1 \mathrm{~mL}$ lysis buffer (50 mM HEPES pH 7.5, $140 \mathrm{mM} \mathrm{NaCl}, 1$ mM EDTA, $1 \%$ Triton X-100, 0.1\% Na-deoxycholate), and then disrupted by a bead-beater (FastPrep-24, MP, California, USA) at $6 \mathrm{~m} / \mathrm{s}$ for $2 \mathrm{~min}$ with $400 \mu \mathrm{L}$ acid-washed glass beads (G8772, Sigma-Aldrich, Missouri, USA). Western blots were carried out using an Anti-His Tag antibody (M30111, Abmart, Shanghai, China) and a horseradish peroxidase-conjugated goat-anti-mouse secondary antibody (074-1806, KPL, USA) as described previously [18].

\section{Fed-batch fermentation}

All fermentations were performed in $5 \mathrm{~L}$ bioreactors (BXBIO, Shanghai, China) with an initial working volume of $1.5 \mathrm{~L}$ as described previously [18]. Inoculum seeds were precultured in Erlenmeyer flasks containing $150 \mathrm{~mL}$ YG medium at $30{ }^{\circ} \mathrm{C}, 220 \mathrm{rpm}$ for $18 \mathrm{~h}$ [18]. After sterilization and cooling, the temperatures of the bioreactors were set to $30{ }^{\circ} \mathrm{C}$. Batch fermentations were started by inoculating with $150 \mathrm{~mL}$ inoculum seeds. After glucose was completely depleted, concentrated mediums consisting of $600 \mathrm{~g} / \mathrm{L}$ glucose, $5 \mathrm{mg} / \mathrm{L}$ biotin, $100 \mathrm{mg} / \mathrm{L}$ calcium pantothenate, and $100 \mathrm{mg} / \mathrm{L}$ niacin were fed into the reactors at rates of $20-35 \mathrm{~mL} / \mathrm{h}$ depending on the dissolved oxygen (DO), which should be maintained above $10 \%$. The pHs were controlled automatically at 5.5 with ammonium hydroxide. Samplings at given intervals were determined for cell densities $\left(\mathrm{OD}_{600} \mathrm{~nm}\right)$ and enzyme activities.

\section{Pretreatment of the corncobs}

Corncobs, purchased from Bei Piao Bang Bang Corncob Development Company (Beijing, China), were ground to a particle size range of $0.25-0.45 \mathrm{~mm}$ ( $40-60$ meshes). For dilute acid pretreatment, corncobs were immersed in an aqueous solution of $2 \%$ diluted sulfuric acid at a solid-to-liquid (S/L) ratio of 1:5. The mixtures were autoclaved at $121{ }^{\circ} \mathrm{C}$ for $1 \mathrm{~h}$. After neutralization with $0.1 \mathrm{~N}$ $\mathrm{NaOH}$, the pretreated corncobs were separated by filtration under vacuum, washed with deionized water, and dried at $80{ }^{\circ} \mathrm{C}$. Aqueous ammonia pretreatment was performed by soaking corncobs with $15 \%$ ammonia in a screw-capped bottle at a solid-liquid ratio of $1: 7$ at $60^{\circ} \mathrm{C}$ for $24 \mathrm{~h}$. After pretreatment, the pretreated corncobs were diluted with four volumes of deionized water, filtrated under vacuum, washed with deionized water until the $\mathrm{pH}$ reached around 7.0 , and dried at $80{ }^{\circ} \mathrm{C}$. Compositions of pretreated corncobs were determined according to National Renewable Energy Laboratory (NREL) procedures LAP-002 and - $005[66,67]$.

\section{Enzymatic saccharification and fermentation}

Enzymatic saccharifications were performed in $150 \mathrm{~mL}$ Erlenmeyer flasks with $2 \mathrm{~g}$ pretreated corncobs in $20 \mathrm{~mL}$ of $50 \mathrm{mM}$ sodium citrate buffer $\mathrm{pH}$ 5.5. The corncobs slurries were autoclaved at $121^{\circ} \mathrm{C}$ for $30 \mathrm{~min}$. After addition of 5 FPU CTec 2 per g corncob or coupled with 300 $\mu \mathrm{L}$ supernatant of the fed-batch fermentation cultures, flasks were stirred in an air incubator shaker at $45{ }^{\circ} \mathrm{C}$, $150 \mathrm{rpm}$. At given intervals, hydrolysates were sampled for analyses of sugar. 
HSFs were conducted in $150 \mathrm{~mL}$ flasks each containing $10 \mathrm{~g}$ of the diluted acid pretreated (DAP) corncobs (with $4.5 \%$ moisture content) or aqueous ammonia pretreated (AAP) corncobs (with 18.6\% moisture content). The corncobs were immersed in $80 \mathrm{~mL}$ of $50 \mathrm{mM}$ sodium citrate buffer $\mathrm{pH} 5.5$ and autoclaved at $121{ }^{\circ} \mathrm{C}$ for $20 \mathrm{~min}$. Following sterilization, $10 \mathrm{FPU} \mathrm{CTec} 2$ per gram corncob was added and enzymatic saccharifications were performed at $45{ }^{\circ} \mathrm{C}, 150 \mathrm{rpm}$ [68]. After $72 \mathrm{~h}, 10 \mathrm{~mL}$ of filter-sterilized media $\left(20 \mathrm{~g} / \mathrm{L} \mathrm{KH}_{2} \mathrm{PO}_{4}, 20 \mathrm{~g} / \mathrm{L}\left(\mathrm{NH}_{4}\right)_{2} \mathrm{SO}_{4}\right.$, $10 \mathrm{~g} / \mathrm{L} \mathrm{MgSO} 4 \cdot 7 \mathrm{H}_{2} \mathrm{O}, 5 \mathrm{~g} / \mathrm{L}$ yeast extract, and $1 \mathrm{~g} / \mathrm{L}$ $\mathrm{MnSO}_{4}$ ) [6] and $1 \mathrm{~mL}$ of fed-batch cultures, collected at $48 \mathrm{~h}$ and adjusted to equal cell densities $\left(\mathrm{OD}_{600 \mathrm{~nm}}, 300\right)$ with sterile deionized water, were added to the corncobs slurries. Sterile deionized water was supplemented to make $100 \mathrm{~mL}$ of the total liquid volume. The flasks were incubated at $30{ }^{\circ} \mathrm{C}$ without stirring. Every $24 \mathrm{~h}, 200 \mu \mathrm{L}$ liquid from each sample was taken, centrifuged and the supernatants were analyzed for the concentrations of glucose, xylose, xylitol, and ethanol.

\section{Analytical methods}

Reducing sugars were determined by the DNS method [69]. HPLC analyses for glucose, xylose, xylitol, and ethanol were performed using a MetaCarb $87 \mathrm{H}$ column $(300 \times 7.8 \mathrm{~mm})$ (Agilent, USA) with a refractive index detector at $35{ }^{\circ} \mathrm{C}$. Twenty microliters of each sample were injected and eluted with $0.01 \mathrm{~N} \mathrm{H}_{2} \mathrm{SO}_{4}$ in water at a rate of $0.6 \mathrm{~mL} / \mathrm{min}$ for $30 \mathrm{~min}$.

\footnotetext{
Abbreviations

SHF: Separate Hydrolysis and Fermentation; CBP: Consolidated bioprocessing; HSF: Hybrid saccharification and fermentation; SSF: Simultaneous saccharification and fermentation; FMDV: Foot-and-Mouth Disease virus; DO: The dissolved oxygen; FPU: Filter paper unit; ORF: Open read frame; IRES: The internal ribosomal entry site; DAP: Diluted acid pretreated; AAP: Aqueous ammonia pretreated.
}

\section{Acknowledgements}

Not applicable.

\section{Authors' contributions}

JZ and HL conceived the study and wrote the manuscript. QL, YD, PW, and XL performed the experiments, acquisition and interpretation of data. YY, BS, JZ, and QL guided the study, analyzed the data, and edited the manuscript. All authors read and approved the final manuscript.

\section{Funding}

This project was sponsored by National Key Research and Development Program of China (2021YFC2100203), Tianjin Synthetic Biotechnology Innovation Capacity Improvement Project (TSBICIP-KJGG-006), National Natural Science Foundation of China (31200022), and Science and Technology Research Program of Shanghai (19DZ2282100).

\section{Availability of data and materials}

All data generated or analyzed during this study are included in this published article.

\section{Declarations}

Ethics approval and consent to participate

Not applicable.

\section{Consent for publication}

All authors have given their consent for the publication.

\section{Competing interests}

The authors declare that they have no competing interests.

\section{Author details}

${ }^{1}$ State Key Laboratory of Genetic Engineering, School of Life Sciences, Fudan University, 2005 Songhu Road, Shanghai 200438, People's Republic of China. ${ }^{2}$ Shanghai Engineering Research Center of Industrial Microorganisms, Fudan University, 2005 Songhu Road, Shanghai 200438, People's Republic of China.

${ }^{3}$ Shanghai Collaborative Innovation Center for Biomanufacturing (SCICB), East China University of Science and Technology, 130 Meilong Road, Shanghai 200237, People's Republic of China. ${ }^{4}$ Key Laboratory for Feed Biotechnology of the Ministry of Agriculture, Feed Research Institute, Chinese Academy of Agricultural Sciences, 12 Zhongguancun South Street, Beijing 100081,

People's Republic of China.

Received: 5 August 2021 Accepted: 10 November 2021

Published online: 22 November 2021

\section{References}

1. Francois JM, et al. Engineering microbial pathways for production of biobased chemicals from lignocellulosic sugars: current status and perspectives. Biotechnol Biofuels. 2020;13:118.

2. Mosier $\mathrm{N}$, et al. Features of promising technologies for pretreatment of lignocellulosic biomass. Bioresour Technol. 2005;96(6):673-86.

3. Hattori T, Morita S. Energy crops for sustainable bioethanol production; which, where and how? Plant Prod Sci. 2010;13(3):221-34.

4. Sethupathy S, et al. Harnessing microbial wealth for lignocellulose biomass valorization through secretomics: a review. Biotechnol Biofuels. 2021;14(1):154

5. Beschkov V. Biogas, biodiesel and bioethanol as multifunctional renewable fuels and raw materials. Front Bioenergy Biofuels. 2017. https://doi. org/10.5772/65734

6. Faga BA, et al. Ethanol production through simultaneous saccharification and fermentation of switchgrass using Saccharomyces cerevisiae D(5) A and thermotolerant Kluyveromyces marxianus IMB strains. Bioresour Technol. 2010;101(7):2273-9.

7. Shi J, et al. Dynamic changes of substrate reactivity and enzyme adsorption on partially hydrolyzed cellulose. Biotechnol Bioeng. 2017;114(3):503-15.

8. Lynd $L R$, et al. How biotech can transform biofuels. Nat Biotechnol. 2008;26(2):169-72.

9. Jiang $\mathrm{Y}$, et al. Consolidated bioprocessing performance of a two-species microbial consortium for butanol production from lignocellulosic biomass. Biotechnol Bioeng. 2020;117(10):2985-95.

10. Kim SM, et al. Promise of combined hydrothermal/chemical and mechanical refining for pretreatment of woody and herbaceous biomass. Biotechnol Biofuels. 2016;9:97.

11. Chang JJ, et al. Constructing a cellulosic yeast host with an efficient cellulase cocktail. Biotechnol Bioeng. 2018;115(3):751-61.

12. Liu $\mathrm{H}$, et al. Engineering microbes for direct fermentation of cellulose to bioethanol. Crit Rev Biotechnol. 2018;38(7):1089-105.

13. Lassmann T, et al. Simulation of the downstream processing in the ethanol production from lignocellulosic biomass with ASPEN Plus ${ }^{\circledR}$ and IPSEpro. Energ Sustain Soc. 2014;4(1):27.

14. Binder JB, Raines RT. Fermentable sugars by chemical hydrolysis of biomass. Proc Natl Acad Sci U S A. 2010;107(10):4516-21.

15. Matsushika A, et al. Ethanol production from xylose in engineered Saccharomyces cerevisiae strains: current state and perspectives. Appl Microbiol Biotechnol. 2009;84(1):37-53. 
16. Fonseca GG, et al. The yeast Kluyveromyces marxianus and its biotechnological potential. Appl Microbiol Biotechnol. 2008;79(3):339-54.

17. Radecka D, et al. Looking beyond Saccharomyces: the potential of nonconventional yeast species for desirable traits in bioethanol fermentation. FEMS Yeast Res. 2015. https://doi.org/10.1093/femsyr/fov053.

18. Zhou J, et al. Improved secretory expression of lignocellulolytic enzymes in Kluyveromyces marxianus by promoter and signal sequence engineering. Biotechnol Biofuels. 2018;11:235.

19. Lobs AK, et al. CRISPR-Cas9-enabled genetic disruptions for understanding ethanol and ethyl acetate biosynthesis in Kluyveromyces marxianus. Biotechnol Biofuels. 2017;10:164

20. Chang JJ, et al. PGASO: A synthetic biology tool for engineering a celIulolytic yeast. Biotechnol Biofuels. 2012;5(1):53.

21. Choo JH, et al. Deletion of a KU80 homolog enhances homologous recombination in the thermotolerant yeast Kluyveromyces marxianus. Biotechnol Lett. 2014;36(10):2059-67.

22. Abdel-Banat BM, et al. Random and targeted gene integrations through the control of non-homologous end joining in the yeast Kluyveromyces marxianus. Yeast. 2010;27(1):29-39.

23. Nonklang S, et al. High-temperature ethanol fermentation and transformation with linear DNA in the thermotolerant yeast Kluyveromyces marxianus DMKU3-1042. Appl Environ Microbiol. 2008;74(24):7514-21.

24. Fang J, et al. Stable antibody expression at therapeutic levels using the 2A peptide. Nat Biotechnol. 2005;23(5):584-90.

25. Ryan MD, et al. Analysis of the aphthovirus $2 \mathrm{~A} / 2 \mathrm{~B}$ polyprotein "cleavage" mechanism indicates not a proteolytic reaction, but a novel translational effect: a putative ribosomal "skip." J of Gen Virol. 2001;82(5):1013-25.

26. de Felipe P, et al. Co-translational, intraribosomal cleavage of polypeptides by the foot-and-mouth disease virus $2 \mathrm{~A}$ peptide. J Biol Chem. 2003;278(13):11441-8.

27. Chen $Y-L$, et al. Directed evolution to produce an alkalophilic variant from a Neocallimastix patriciarum xylanase. Can J Microbiol. 2001;47(12):1088-94.

28. Shallom D, Shoham Y. Microbial hemicellulases. Curr Opin Microbiol. 2003;6(3):219-28.

29. Doronina VA, et al. Site-specific release of nascent chains from ribosomes at a sense codon. Mol Cell Biol. 2008;28(13):4227-39.

30. Souza-Moreira TM, et al. Screening of $2 A$ peptides for polycistronic gene expression in yeast. FEMS Yeast Res. 2018. https://doi.org/10.1093/femsyr/ foy036.

31. Roongsawang $\mathrm{N}$, et al. Coexpression of fungal phytase and xylanase utilizing the cis-acting hydrolase element in Pichia pastoris. FEMS Yeast Res. 2010;10(7):909-16.

32. Trichas $\mathrm{G}$, et al. Use of the viral $2 \mathrm{~A}$ peptide for bicistronic expression in transgenic mice. BMC Biol. 2008;6:40.

33. Fernandes $L D$, et al. Gene length as a regulator for ribosome recruitment and protein synthesis: theoretical insights. Sci Rep. 2017;7(1):17409.

34. Morillo-Huesca M, et al. A simple in vivo assay for measuring the efficiency of gene length-dependent processes in yeast mRNA biogenesis. FEBS J. 2010;273(4):756-69.

35. Ohgren $\mathrm{K}$, et al. Effect of hemicellulose and lignin removal on enzymatic hydrolysis of steam pretreated corn stover. Bioresour Technol. 2007:98(13):2503-10

36. García-Aparicio MP, et al. Xylanase contribution to the efficiency of cellulose enzymatic hydrolysis of barley straw. Appl Biochem Biotechnol. 2007;137-140(1-12):353-65.

37. Várnai A, et al. Restriction of the enzymatic hydrolysis of steampretreated spruce by lignin and hemicellulose. Enzyme Microb Tech. 2010;46(3-4):185-93.

38. Saitoh $\mathrm{S}$, et al. Co-fermentation of cellulose/xylan using engineered industrial yeast strain OC-2 displaying both beta-glucosidase and betaxylosidase. Appl Microbiol Biotechnol. 2011;91(6):1553-9.

39. Alvira $P$, et al. Effect of endoxylanase and alpha-L-arabinofuranosidase supplementation on the enzymatic hydrolysis of steam exploded wheat straw. Bioresour Technol. 2011;102(6):4552-8.

40. Zhou J, et al. Biochemical and kinetic characterization of $\mathrm{GH} 43$ beta-Dxylosidase/alpha-L-arabinofuranosidase and GH30 alpha-L-arabinofuranosidase/beta-D-xylosidase from rumen metagenome. J Ind Microbiol Biotechnol. 2012;39(1):143-52.
41. Banerjee $\mathrm{G}$, et al. Rapid optimization of enzyme mixtures for deconstruction of diverse pretreatment/biomass feedstock combinations. Biotechnol Biofuels. 2010;3:22.

42. Varnai A, et al. Synergistic action of xylanase and mannanase improves the total hydrolysis of softwood. Bioresour Technol. 2011;102(19):9096-104.

43. Inoue $\mathrm{H}$, et al. Effect of beta-mannanase and beta-mannosidase supplementation on the total hydrolysis of softwood polysaccharides by the Talaromyces cellulolyticus cellulase system. Appl Biochem Biotechnol. 2015;176(6):1673-86

44. Katsimpouras $\mathrm{C}$, et al. A thermostable $\mathrm{GH} 26$ endo-beta-mannanase from Myceliophthora thermophila capable of enhancing lignocellulose degradation. Appl Microbiol Biotechnol. 2016;100(19):8385-97.

45. Verduyn C, et al. Effect of benzoic acid on metabolic fluxes in yeasts: a continuous-culture study on the regulation of respiration and alcoholic fermentation. Yeast. 1992:8(7):501-17.

46. Postma $\mathrm{E}$, et al. Enzymic analysis of the crabtree effect in glucose-limited chemostat cultures of Saccharomyces cerevisiae. Appl Environ Microbiol. 1989;55(2):468.

47. Dashko $S$, et al. Why, when, and how did yeast evolve alcoholic fermentation? FEMS Yeast Res. 2014;14(6):826-32.

48. Remond $\mathrm{C}$, et al. Combination of ammonia and xylanase pretreatments: impact on enzymatic xylan and cellulose recovery from wheat straw. Bioresour Technol. 2010;101(17):6712-7.

49. Shin HD, et al. Novel Aspergillus hemicellulases enhance performance of commercial cellulases in lignocellulose hydrolysis. Biotechnol Prog. 2011:27(2):581-6.

50. Liu K, et al. High concentration ethanol production from corncob residues by fed-batch strategy. Bioresour Technol. 2010;101(13):4952-8.

51. Tenkanen $\mathbf{M}$, et al. Investigation of lignin-carbohydrate complexes in kraft pulps by selective enzymatic treatments. Appl Microbiol Biotechnol. 1999;51(2):241-8

52. Gao J, et al. Transcriptional analysis of Kluyveromyces marxianus for ethanol production from inulin using consolidated bioprocessing technology. Biotechnol Biofuels. 2015:8:115.

53. Mo W, et al. Kluyveromyces marxianus developing ethanol tolerance during adaptive evolution with significant improvements of multiple pathways. Biotechnol Biofuels. 2019;12:63.

54. Santharam $L$, et al. Effect of aeration and agitation on yeast inulinase production: a biocalorimetric investigation. Biopro Biosyst Eng. 2019;42(6):1-13.

55. Hensing MC, et al. Production of extracellular inulinase in high-celldensity fed-batch cultures of Kluyveromyces marxianus. Appl Microbiol Biotechnol. 1994;42(4):516-21.

56. Xin D, et al. Comparison of aqueous ammonia and dilute acid pretreatment of bamboo fractions: Structure properties and enzymatic hydrolysis. Biores Technol. 2015;175:529-36.

57. Hua Y, et al. Release of glucose repression on xylose utilization in Kluyveromyces marxianus to enhance glucose-xylose co-utilization and xylitol production from corncob hydrolysate. Microb Cell Fact. 2019;18(1):24.

58. Rodrussamee N, et al. Growth and ethanol fermentation ability on hexose and pentose sugars and glucose effect under various conditions in thermotolerant yeast Kluyveromyces marxianus. Appl Microbiol Biotechnol. 2011;90(4):1573-86.

59. Gschaedler A, et al. Use of non-Saccharomyces yeasts in cider fermentation: importance of the nutrients addition to obtain an efficient fermentation. Int J Food Microbiol. 2021;347:109169.

60. Ma Y, Liu Y. Turning food waste to energy and resources towards a great environmental and economic sustainability: An innovative integrated biological approach. Biotechnol Adv. 2019;37(7):107414.

61. Pang $\mathrm{H}$, et al. Enhancing volatile fatty acids production from waste activated sludge by a novel cation-exchange resin assistant strategy. J Clean Prod. 2021;278:123236.

62. You C, et al. Potential hydrophobic interaction between two cysteines in interior hydrophobic region improves thermostability of a family 11 xylanase from Neocallimastix patriciarum. Biotechnol Bioeng. 2010;105(5):861-70

63. Gibson DG, et al. Enzymatic assembly of DNA molecules up to several hundred kilobases. Nat Methods. 2009;6(5):343-5. 
64. Antunes DF, et al. A simple and rapid method for lithium acetate-mediated transformation of Kluyveromyces marxianus cells. World J Microb Biot. 2000;16(7):653-4

65. Pan $X$, et al. High level expression of a truncated beta-mannanase from alkaliphilic Bacillus sp. N16-5 in Kluyveromyces cicerisporus. Biotechnol Lett. 2011;33(3):565-70.

66. Sluiter A, et al. Determination of sugars, byproducts, and degradation products in liquid fraction process samples. Golden: NREL Analytical Procedure National Renewable Energy Laboratory; 2006.

67. Sluiter A, et al. Determination of structural carbohydrates and lignin in biomass. Golden: NREL Analytical Procedure National Renewable Energy Laboratory; 2004
68. Rehman O, et al. Optimization of low-temperature energy-efficient pretreatment for enhanced saccharification and fermentation of Conocarpus erectus leaves to produce ethanol using Saccharomyces cerevisiae. Biomass Convers Bior. 2019;10(4):1269-78.

69. Miller GL. Use of dinitrosalicylic acid reagent for determination of reducing sugar. Anal Chem. 1959;31(3):426-8.

\section{Publisher's Note}

Springer Nature remains neutral with regard to jurisdictional claims in published maps and institutional affiliations.
Ready to submit your research? Choose BMC and benefit from:

- fast, convenient online submission

- thorough peer review by experienced researchers in your field

- rapid publication on acceptance

- support for research data, including large and complex data types

- gold Open Access which fosters wider collaboration and increased citations

- maximum visibility for your research: over 100M website views per year

At BMC, research is always in progress.

Learn more biomedcentral.com/submissions 